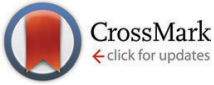

Cite this: J. Mater. Chem. C, 2016, 4, 2979

Received 15th October 2015, Accepted 14th December 2015

DOI: $10.1039 / \mathrm{c} 5 t \mathrm{tc} 03352 \mathrm{~g}$

www.rsc.org/MaterialsC

\section{Polymorphism-dependent aggregation induced emission of a push-pull dye and its multi-stimuli responsive behavior $\dagger$}

\author{
Chiara Botta, ${ }^{* a}$ Sara Benedini, ${ }^{\mathrm{b}}$ Lucia Carlucci, ${ }^{\mathrm{c}}$ Alessandra Forni, ${ }^{* \mathrm{de}}$ \\ Daniele Marinotto, ${ }^{c}$ Andrea Nitti, ${ }^{b}$ Dario Pasini, ${ }^{\text {bf }}$ Stefania Righetto ${ }^{c e}$ and \\ Elena Cariati*ce
}

\begin{abstract}
A comprehensive optical investigation of 1,1-dicyano-2,2-bis(4-dimethylaminophenyl)ethylene (1) is presented. The compound crystallizes in four different forms all displaying AIE behavior. The crystalline forms $\mathbf{A}$ and $\mathbf{B}$ are yellow-orange-emissive, while $\mathbf{C}$ and $\mathbf{D}$ are green-emissive. On the basis of $\mathbf{X}$-ray structural analysis, the weak intermolecular interactions account for restricted internal rotations, leading to fluorescence enhancement in the crystals; however, the difference in emission color is ascribed to the various conformations of the molecules in the four crystalline forms. In addition, the emission color of crystals of $\mathbf{A}$ can be tuned by heating and grinding, that of $\mathbf{B}$ by grinding only, while crystals of $\mathbf{C}$ show chronochromic behavior. An explanation for such a rich variety of luminescence behavior is formulated here through the use of steady state and time resolved photoluminescence, $\mathrm{X}$-ray diffraction analysis and DFT and TDDFT calculations. The involved chromic mechanism appears to be mainly associated with surface defects induced by the external stimuli rather than an amorphization process, as frequently observed for other stimuli responsive compounds.
\end{abstract}

\section{Introduction}

Organic materials that exhibit strong emission in the aggregated state have aroused much interest in recent years because of their potential applications in optical and optoelectronic devices such as light-emitting diodes, ${ }^{1}$ optical waveguides ${ }^{2}$ and optically pumped lasers. ${ }^{3} \mathrm{D}-\pi-\mathrm{A}$ type dyes usually exhibit unique fluorescence properties due to their intramolecular charge transfer (ICT) transitions, which endow them with tuned electronic states under various conditions. ${ }^{4}$

However, aggregation-caused quenching (ACQ) often takes place in the condensed phases for most $\mathrm{D}-\pi-\mathrm{A}$ luminogens, ${ }^{5}$

\footnotetext{
${ }^{a}$ ISMAC-CNR, Istituto per lo Studio delle Macromolecole - Consiglio Nazionale delle Ricerche, Via Corti 12, 20133 Milano, Italy. E-mail: c.botta@ismac.cnr.it

${ }^{b}$ Department of Chemistry, University of Pavia, Viale Taramelli 10, 27100 Pavia, Italy. E-mail: dario.pasini@unipv.it

${ }^{c}$ Department of Chemistry, University of Milano, via Golgi 19, 20133 MilanoItaly. E-mail: elena.cariati@unimi.it

${ }^{d}$ ISTM-CNR, Istituto di Scienze e Tecnologie Molecolari - Consiglio Nazionale delle Ricerche, via Golgi 19, 20133 Milano, Italy. E-mail: alessandra.forni@istm.cnr.it ${ }^{e}$ INSTM Research Unit, University of Milano, Italy

${ }^{f}$ INSTM Research Unit, University of Pavia, Italy

$\dagger$ Electronic supplementary information (ESI) available: Experimental details, crystal data, photoluminescence, XRPD and additional computational information. CCDC 1431281--1431284. For ESI and crystallographic data in CIF or other electronic format see DOI: 10.1039/c5tc03352g
}

limiting their real-world applications. In recent years, Tang and other groups have reported several types of organic molecules which show an unusual luminescence behavior; they are weak or non-emissive in solution, but show enhanced efficiency in the solid states. ${ }^{6}$ Such aggregation-induced-(enhanced) emission $(\mathrm{AI}(\mathrm{E}) \mathrm{E})$ is frequently ascribed to restricted internal rotations (RIR). ${ }^{6,7}$ For applications in optoelectronic devices as well as sensors $^{8}$ and memories, ${ }^{9}$ emissive materials whose emission intensities and colors can be tuned are highly desirable. However, variation of the solid state luminescence color is less affordable than in solution due to the difficulty in obtaining different stable phases in the aggregated state with varied molecular conformations. This goal can be reached either by obtaining a compound crystallizing in different polymorphs or by altering the molecular geometry and/or packing mode by external stimuli, especially heat, ${ }^{10}$ solvent vapor ${ }^{11}$ and mechanical perturbation ${ }^{12}$ (including shearing, grinding, smashing or elongation), allowing to control solid state luminescence (thermo-, vapo- and mechanochromism respectively). In some cases, the emission properties show variations in time, at room temperature and without the need for external stimuli, a behavior named chronochromism. This process was reported for AIE materials recovering their initial state from a metastable state generated by an external stimulus (self-healing effect) ${ }^{13,14}$ or for materials that undergo spontaneous transition towards a more stable crystal phase. ${ }^{15}$ 


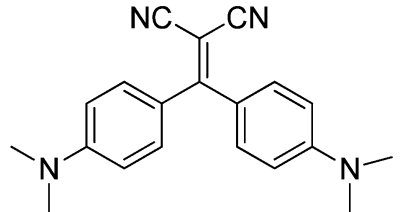

Scheme 1 Chemical structure of compound 1.

In some cases the chromic variations are associated with changes in the crystal packing (different polymorphs), more frequently to a switch between crystalline/amorphous phases. More intriguing are fluorophores displaying sharp variations in the emissive properties while maintaining the same crystal structure. Few examples of this chromic behavior have been reported so far but a definitive explanation is still lacking. Possible explanations rely on the particle size and the surface structure of solids. ${ }^{16 a}$ In particular, different electronic processes have been hypothesized in the bulk and at the surface of microcrystals so that two emission centers, one in the middle and another in the periphery of the solids, are responsible for the whole luminescence. ${ }^{16,17}$

We have previously reported on the efficient AIE properties of a series of "push-pull" dyes possessing common structural features: a trisubstituted ethylene core, decorated with two carboxylate esters and a 4-dialkylaminophenyl branch as the third substituent. ${ }^{18 a}$ Studying in detail one of the AIE active compounds using ultrafast pump-probe spectroscopy combined with calculations, we have given direct evidence that the restriction of the intramolecular rotation is the key process for switching on the AIE properties. ${ }^{19}$

In this paper, we report the interesting emissive behavior of 1,1-dicyano-2,2-bis(4-dimethylaminophenyl)ethylene, 1 (see Scheme 1), displaying AIE and structure dependent chromic properties. In particular, four different crystalline forms have been isolated: the yellow-orange-emissive form $\mathbf{A}$, the yellow-emissive form $\mathbf{B}$ and the green-emissive forms $\mathbf{C}$ and $\mathbf{D}$, the latter containing a co-crystallized $\mathrm{CH}_{2} \mathrm{Cl}_{2}$ molecule. Their stimuli responsive emissive behavior is analyzed here by fluorescence spectroscopy, X-ray diffraction analysis and computational methods.

\section{Experimental}

UV-Vis absorption spectra were obtained using a Perkin Elmer Lambda 900 spectrometer and PL spectra using a SPEX $270 \mathrm{M}$ monochromator equipped with a $\mathrm{N}_{2}$ cooled chargecoupled device excited using a monochromated $450 \mathrm{~W}$ Xe lamp. Spectra were corrected for the instrument response. Photoluminescence quantum yields (PL QYs) of solutions were obtained by using quinine sulfate or anthracene as standard. PL QYs of crystals and powders were obtained by using a homemade integrating sphere, as previously reported. ${ }^{20}$ Fluorescence microscopy images were collected using a Nikon Eclipse TE2000-U inverted confocal microscope. Excitation was performed using a $100 \mathrm{~W} \mathrm{Hg}$ lamp and a 330-380 nm band-pass excitation filter or a $405 \mathrm{~nm}$ laser. Spectra were recorded by connecting the confocal microscope with the monochromator using an optical fiber.

Lifetime measurements and Time Resolved Emission Spectra (TRES) were performed using an Edinburgh Picosecond Pulsed Diode Laser EPL-UV 375 (Edinburg Instruments Ltd) at a repetition rate of $20 \mathrm{MHz}$ to $50 \mathrm{kHz}$ and a pulse width of 66 ps. The dynamics of emission decay were monitored by using the FLS980s time-correlated single-photon counting.

Diffraction data for single crystals of A-D were collected on a Bruker Smart Apex II CCD area detector using graphitemonochromated Mo-K $\alpha$ radiation. Data reduction was made using SAINT programs; absorption corrections based on multiscan were obtained using SADABS. ${ }^{21}$ The structures were solved using SHELXS- $97^{22}$ and refined on $\mathrm{F}^{2}$ by full-matrix least-squares using SHELXL-97. ${ }^{22}$ All the non-hydrogen atoms were refined anisotropically, hydrogen atoms were included as 'riding' and not refined. Powder patterns were recorded on Philips PW1820 and Bruker AXS D8 diffractometers (Cu-K $\alpha$ radiation, $\lambda=1.5405 \AA$ ) in the $5-40^{\circ} 2 \theta$ range $\left(0.02^{\circ}\right.$ and $1.5 \mathrm{~s}$ per step). All calculations have been performed using the Gaussian suite of programs. ${ }^{23}$ Geometry optimization of the ground state $\left(\mathrm{S}_{0}\right)$ has been performed at the PBE0/6-311++G(d,p $)^{24}$ level of theory, starting from the experimental X-ray geometry of polymorph A. We imposed a $C_{2}$ symmetry constraint since the free optimization led to a quasisymmetrical structure. Standard vertical Time Dependent (TD) DFT calculations were then carried out at the $C_{2}$ optimized geometry using the same functional and basis set to determine the excited state properties. Up to 20 vertical excitations from $S_{0}$ have been evaluated, including both singlet and triplet excited states. The lower energy singlet excited state $\left(\mathrm{S}_{1}\right)$ was then submitted to TD-PBE0/6-311++G(d,p) geometry optimization to evaluate the emission from $S_{1}$ to $S_{0}$. Excited state optimization required to remove the $C_{2}$ symmetry constraint to get a stationary point. The performance of the PBE0 functional in describing the electronic and optical properties of the present compound has been assessed together with that of other exchange-correlation functionals (CAM-B3LYP and M062X) generally suggested, besides PBE0, as the outperforming ones for optical property calculations on organic chromophores ${ }^{25}$ (see ESI $\dagger$ ). All calculations were carried out in toluene using the conductor-like polarizable continuum model, CPCM. ${ }^{26}$ For TDDFT calculations the linear response approach has been adopted. ${ }^{27}$

\section{Results and discussion}

\section{Molecular optical properties}

Compound 1 was synthesized modifying a literature procedure (see $\mathrm{ESI} \dagger$ ). ${ }^{28}$ UV-vis absorption and emission spectra of $\mathbf{1}$ in different solvents are reported in Fig. 1. Positive solvatochromism is observed for both, being stronger for the emission spectra indicating that the excited state is more polar than the ground one.

The compound's emission QY in good solvents is very low $(<0.1 \%)$, but an intensification of the emission is observed after introducing poor solvents (Fig. 2a and Fig. S4, ESI $\dagger$ ). 


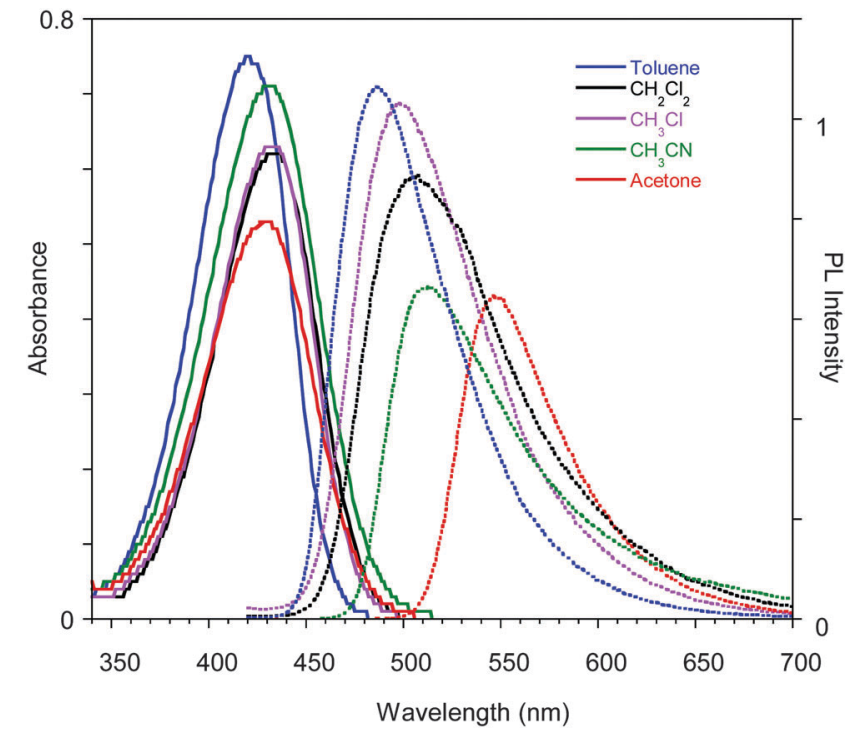

Fig. 1 Optical absorption and emission spectra of 1 in different solvents.

This observation suggests an Aggregation Induced Emission (AIE) behavior associated with the formation of aggregates of 1 by addition of poor solvents, as reported earlier. ${ }^{18}$ The fluorescence intensity of $\mathbf{1}$ in acetone and acetone/water mixtures (retaining a concentration of $10^{-5} \mathrm{M}$ ) with increasing water (non-solvent) fraction up to $90 \%$ are reported in the inset of Fig. 2a. The emission intensity (QY of about $0.07 \%$ ) of the solutions is not affected by the non-solvent addition up to $80 \%$ water fraction. At higher water concentrations the emission intensity increases (by a factor of 25 at $90 \%$ water content), the band shape sharpens and slightly $(5 \mathrm{~nm})$ red-shifts. These variations start in the first minutes after non-solvent addition to the acetone solution with a temporal evolution that depends on the water content, as recently reported. ${ }^{14}$ The fastest variations are observed for the highest water volume: the maximum of the emission intensity is obtained in about 40 and $20 \mathrm{~min}$ for water fractions of 85 and $90 \%$, respectively. At longer times a reduction in the emission intensity is observed, probably due to the precipitation of large aggregates, while the emission retains its sharp spectral shape. The time evolution of the emission spectra for the $85 \%$ water content solution is reported as an example in Fig. 2a.

In order to support a Restricted Intramolecular Rotation (RIR) mechanism at the origin of the emission intensification, as is often the case for AIE fluorophores, the spectra of a diluted $\left(3.5 \times 10^{-5} \mathrm{M}\right)$ good solvent (THF) solution at room temperature and at temperatures down to the solidification point of the solvent have been collected (see Fig. 2b). While at room temperature the emission is very weak, below the solidification point of the solvent (about $165 \mathrm{~K}$ ), where the molecular motions are blocked, an increase in the emission intensity is observed, reaching a factor of about 300 at $110 \mathrm{~K}$. Below $120 \mathrm{~K}$ the PL spectrum of the solution shows a narrowing of the profile and blue-shifts to $510 \mathrm{~nm}$ at $80 \mathrm{~K}$. Moreover, the appearance of a new band at $595 \mathrm{~nm}$ is observed below $100 \mathrm{~K}$.
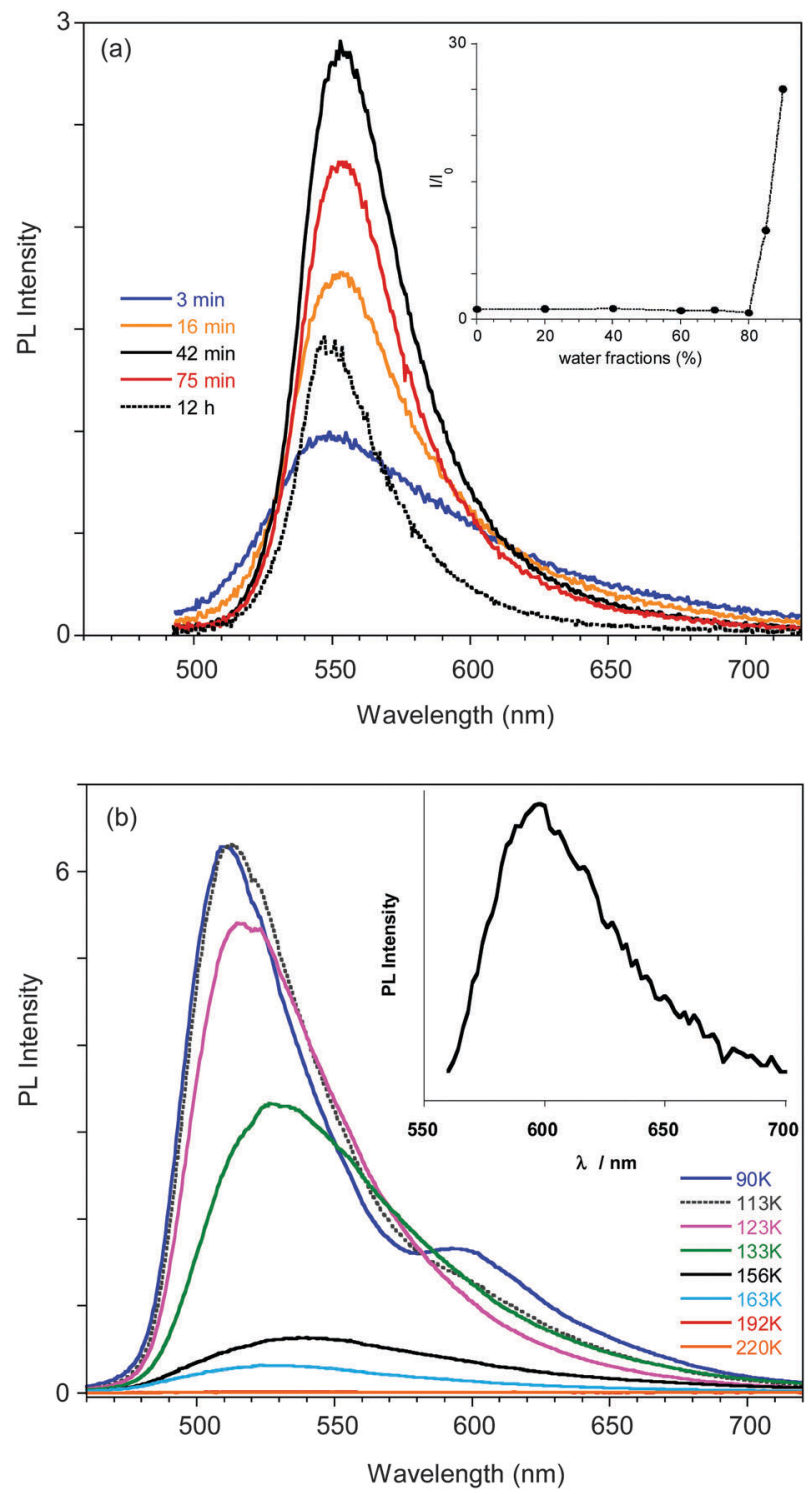

Fig. 2 (a) Emission spectra of a solution of 1 in acetone $/ \mathrm{H}_{2} \mathrm{O}$ (concentration $1 \times 10^{-5} \mathrm{M}$ ) with $85 \%$ water measured at different delay times from water addition. In the inset the intensity of the emission for different water fractions (normalized with respect to the intensity at $0 \%$ water) is reported, as measured just after water addition. (b) Emission spectra of a THF solution of 1 at different temperatures. In the inset the PL emission at $77 \mathrm{~K}$ measured at $2.5 \mu$ s delay is reported.

A deeper analysis of the low temperature emissive behavior performed by time resolved spectroscopy (see ESI $\dagger$ ) revealed a fast decay (biexponential with $3.70 \mathrm{~ns}$ of average lifetime) for the $510 \mathrm{~nm}$ peak while much slower decay (with an average lifetime of $0.93 \mu \mathrm{s}$ ) is measured at $620 \mathrm{~nm}$, suggesting a phosphorescence origin of the low energy band. The emission spectrum recorded at long delay times $(2.5 \mu \mathrm{s})$ in order to cut the fluorescence emission is shown in the inset of Fig. $2 b$, confirming the phosphorescence origin of the $595 \mathrm{~nm}$ peak observed in the steady state spectrum at temperatures below $100 \mathrm{~K}$.

A phosphorescence band is known to appear in aromatic amines, particularly in $N$-alkylamines,${ }^{29}$ and has been ascribed 
to the not strict parallelism between the lone-pair orbital on the nitrogen atom and the $\pi$-electron system of the aromatic ring, which determines nonvanishing terms in the matrix elements of spin-orbit coupling. ${ }^{30}$ The increase of the CT character of the lower-lying electronic states is expected to increase the transition moment from the first excited triplet state $\mathrm{T}_{1}$ and the ground state $\mathrm{S}_{0}{ }^{30}$ In the presently investigated push-pull compound $\mathbf{1}$, the $\mathrm{N}$-dimethyl groups are only slightly rotated with respect to the benzene rings to which they are bonded, ${ }^{31}$ but the large CT character of the low energy transitions (vide infra) is expected to result in non-null phosphorescence yield, detectable only at low temperature.

\section{Quantum chemical calculations}

The $421 \mathrm{~nm}$ absorption of 1 in toluene is well reproduced by TD-PBE0/6-311++G(d,p) calculations on the optimized PBE0/ $6-311++G(d, p)$ geometry (see Fig. 3) which provided, in the same solvent, excitation energies $S_{0} \rightarrow S_{1}$ and $S_{0} \rightarrow S_{2}$ at 415 and $408 \mathrm{~nm}$, respectively, characterized by similar oscillator strengths ( $f=0.71$ and 0.47 , respectively) and associated almost totally (99\%) with HOMO-1 $\rightarrow$ LUMO and HOMO $\rightarrow$ LUMO transitions, respectively. The involvement of two transitions in the observed absorption band is confirmed by a slight skewness of the absorption profiles (see Fig. 1).

Though very close in energy, the two transitions have a different nature because the two involved occupied MOs, HOMO-1 and HOMO, have quite different delocalization schemes (see Fig. S3 (ESI $\dagger$ ) for a plot of the Frontier MOs, FMOs). While HOMO-1 is concentrated on the electron-donor dimethylamino-phenyl groups, the HOMO is delocalized on the whole molecule, though with larger contributions on the electron-donor groups. The LUMO is as well distributed on the whole molecule with larger contributions on the electronacceptor CN groups. Such FMO delocalization scheme, which is almost invariably reproduced by other DFT functionals (see Fig. S3, ESI $\dagger$ ), appears to be different from that usually found in other push-pull cross-conjugated architectures, which are characterized by spatially disjoint distributions of HOMOs and

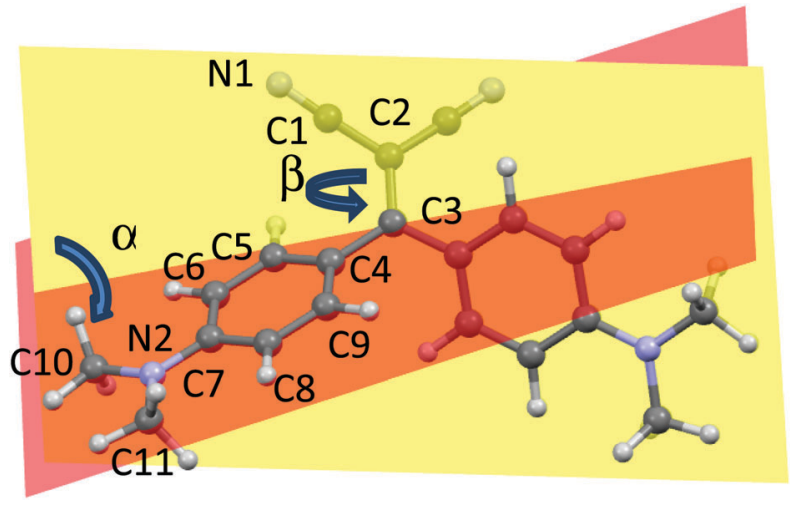

Fig. 3 Optimized PBE0/6-311++G(d,p) geometry of 1 with atom numbering scheme. $\alpha$ is the dihedral angle between the planes through the carbon atoms of the phenyl rings, plotted in yellow and orange, respectively; $\beta$ is the $\mathrm{C} 1-\mathrm{C} 2=\mathrm{C} 3-\mathrm{C} 4$ torsion angle.
LUMOs. $^{32}$ Both transitions involve a charge transfer from the push to pull moieties of the molecule, with an increase of the computed dipole moment from the ground $\left(\mu_{\mathrm{g}}=13.9 \mathrm{D}\right)$ to $S_{1}$ and $S_{2}$ excited states ( $\mu_{\mathrm{e}}=19.1$ and $15.7 \mathrm{D}$, respectively), in agreement with the observed stronger solvatochromism of the excited state with respect to the ground state.

To investigate the origin of the proposed AIE behavior of $\mathbf{1}$, TD-PBE0/6-311++G(d,p) optimization of the $S_{1}$ excited state in toluene has been performed, leading to a stationary state characterized by a remarkable conformational rearrangement of the molecule. Starting from the optimized $S_{0}$ geometry, where the dimethylamino-phenyl groups are significantly tilted with respect to one another (the dihedral angle $\alpha$ between the least-squares planes through the phenyl carbon atoms measures $65.1^{\circ}$ ), optimization of $S_{1}$ leads to a geometry where one dimethylamino-phenyl group is coplanar with the two cyano groups, forming a highly conjugated system with them, while the other one is almost perpendicular to this plane (see Fig. S5, ESI $\dagger$ ). Emission from $\mathrm{S}_{1}$, computed at $587 \mathrm{~nm}$, principally (99\%) involves a transition from the LUMO, which is delocalized on the conjugated system, to the HOMO, which is distributed essentially on the perpendicular dimethylaminophenyl group (see Fig. S5 (ESI $\dagger$ ) for a FMO plot of the $\mathrm{S}_{1}$ optimized state). Owing to the perpendicular arrangement of the two molecular groups in the excited state and the consequent negligible FMO spatial overlap, the oscillator strength of the emission is zero. These results are in agreement with the experimental observation of the poor emissive behavior of 1 in good solvents and further support the hypothesis that the AIE behavior is connected to a RIR mechanism, which prevents the formation of the highly conjugated non-emissive excited state.

Further TDDFT calculations have been performed on $\mathbf{1}$ at the ground-state geometry optimized in toluene, by including triplet excitations in order to support the hypothesis of phosphorescence emission experimentally detected at low temperature. The $\mathrm{T}_{2}$ state, computed at $509 \mathrm{~nm}$, was found to be relatively close to the $S_{1}$ state $\left(\Delta E_{\mathrm{S}_{1} \mathrm{~T}_{2}}=0.53 \mathrm{eV}\right)$ (see Scheme 2) and share with it the same character (mainly HOMO-1 $\rightarrow$ LUMO transition, see above), where the HOMO-1 orbital has a large

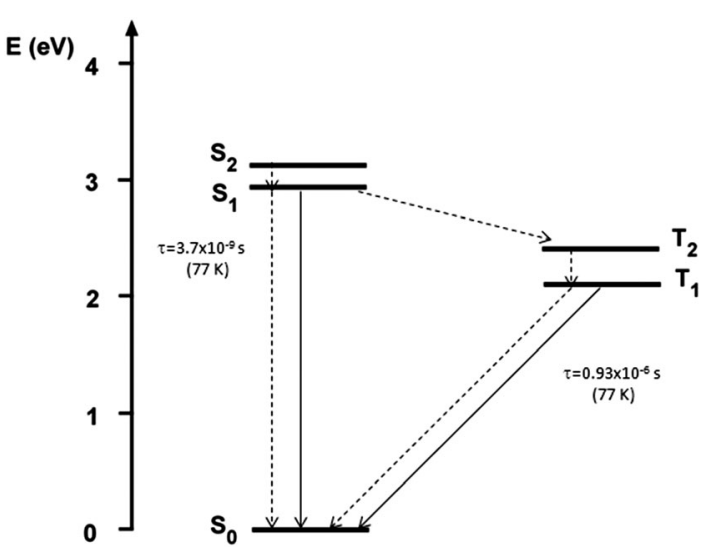

Scheme 2 Jablonski diagram of compound 1 ( $\tau$ values are measured in THF at $77 \mathrm{~K}$ ). 
contribution (32\%) from the lone-pair electrons of the amine nitrogen atoms. To the first order, spin-orbit coupling is forbidden between states with the same configuration, ${ }^{33}$ and this, in addition to the non-negligible $\Delta E_{\mathrm{S}_{1} \mathrm{~T}_{2}}$ gap, should further decrease the efficiency of the $S_{1} \rightarrow T_{2}$ process in the present compound. These results are in agreement with the observed low phosphorescence yield, unlike room temperature phosphorescent organic compounds ${ }^{34}$ characterized by quite smaller $\Delta E_{\mathrm{S}_{1} \mathrm{~T}_{2}}$ and different $\mathrm{S}_{1}-\mathrm{T}_{2}$ configurations. Finally, the $\mathrm{T}_{1}$ state, having the same character as $\mathrm{S}_{2}$ (mainly HOMO $\rightarrow$ LUMO transition), was computed at $587 \mathrm{~nm}$, very close to the experimental phosphorescence band (595 $\mathrm{nm})$.

\section{Crystal structures}

Interestingly, four kinds of crystals of $\mathbf{1}$ were obtained by slow precipitation from a solution of dichloromethane/hexane. The crystals are characterized by different morphologies and absorption and emission colors. In particular, orange (orange emissive) crystals of prismatic shape (referred to as A), orange rod-like (yellow emissive) crystals (referred to as B), greenyellow (green emissive) needles (referred to as $\mathbf{C}$ ) and yellow (green emissive) plate (referred to as D) were isolated and their crystal structure determined (see Table S2, ESI $\dagger$ ). The crystal structures of two forms of $\mathbf{1}$, synthesized through alternative routes by Suzuki et al. ${ }^{35}$ and Bures et al., ${ }^{36}$ were previously published without optical characterization. Polymorph A displays a crystal structure corresponding to that previously determined by Suzuki et al.; it belongs to the $C 2 / c$ space group with half a molecule in the asymmetric unit (a.u.). Crystals of $\mathbf{B}$ as well belong to the $C 2 / c$ space group with half a molecule in the a.u., while crystals of $\mathbf{C}$ belong to the non-centrosymmetric $P 2_{1}$ space group with two molecules in the a.u. Crystals of $\mathbf{D},^{36}$ which include dichloromethane as a co-crystallized solvent, belong to the $P 2_{1} / c$ space group with one molecule in the a.u. A distinctive feature of the molecular structures of A-D is their twisted conformation due to sterical hindrance both between the $\mathrm{CN}$ and the dimethylamino-phenyl substituents and between the phenyl rings. Three geometrical factors can play in a concerted way to reduce such hindrance (see Fig. 3): (i), the $(\mathrm{N}) \mathrm{C}-\mathrm{C}=\mathrm{C}-\mathrm{C}(\mathrm{Ph})$ torsion angle $\beta$; (ii), the reciprocal tilting of the phenyl rings, which can be quantified through the dihedral angle $\alpha$ between the least-squares planes through the phenyl carbon atoms; and (iii) the central double bond, which is significantly elongated with respect to the value of 1.331(9) $\AA$ reported for $\left(\mathrm{C}_{2}\right)-\mathrm{C}=\mathrm{C}-\left(\mathrm{C}_{2}\right)$ unconjugated bonds ${ }^{37}$ denoting a high conjugation degree for the present compound. It is to be pointed out that, owing to the cross-conjugated architecture of $1,{ }^{38}$ the phenyl rings, connected with each other by two single bonds, are separately conjugated to each CN group, as well as the CN groups are separately conjugated to each phenyl ring. The observed conformational differences in the four crystals (see Table 1), though small, are associated with a different conjugation degree between the molecular moieties connected through the $\mathrm{C}=\mathrm{C}$ double bond, as indicated by the reported bond lengths. In particular, the lower the dihedral angle between the phenyl rings, the larger the distortion
Table $1(\mathrm{~N}) \mathrm{C}-\mathrm{C}=\mathrm{C}-\mathrm{C}(\mathrm{Ph})$ torsion angles $\left(\beta,{ }^{\circ}\right)$, dihedral angles $\left(\alpha,{ }^{\circ}\right)$ between the least-squares planes through the phenyl rings and selected bond lengths $(\AA)$ for $A-D^{a}$

\begin{tabular}{llllll}
\hline & $\beta$ & $\alpha$ & $\mathrm{C}=\mathrm{C}$ & $\mathrm{C}-\mathrm{C}(\mathrm{CN})$ & $\mathrm{C}-\mathrm{C}(\mathrm{Ph})$ \\
\hline $\mathbf{C}$ & $11.8(1)^{b}$ & $71.8(1)^{d}$ & $1.376(3)^{e}$ & $1.436(3)^{f}$ & $1.466(3)^{g}$ \\
$\mathbf{D}$ & $14.8(1)^{c}$ & $62.8(1)$ & $1.381(3)$ & $1.433(3)^{h}$ & $1.464(3)^{i}$ \\
$\mathbf{B}$ & $18.0(1)$ & $59.4(1)$ & $1.390(2)$ & $1.431(2)$ & $1.461(2)$ \\
$\mathbf{A}$ & $19.9(1)$ & $58.0(1)$ & $1.387(2)$ & $1.429(2)$ & $1.459(2)$
\end{tabular}

${ }^{a}$ See also Fig. 3 for the definition of geometrical parameters $\alpha$ and $\beta$. ${ }^{b}$ Average over the absolute values of the four torsions around the double bonds of the two independent molecules, 10.2(4), 8.8(4) and -13.3(4), $-15.1(3)^{\circ}$, respectively. ${ }^{c}$ Average over the two non-equivalent torsions around the double bond, 15.5(1) and 14.1(1). ${ }^{d}$ Average over the values observed for the two independent molecules, 75.8(1) and 67.9(1) ${ }^{\circ}$, respectively. ${ }^{e}$ Average over: $1.370(3), 1.382(3) \AA .{ }^{f}$ Average over: 1.438(3), 1.432(4), 1.433(4), 1.440(3) Å. ${ }^{g}$ Average over: 1.469(3), 1.463(3), 1.457(3), 1.474(3) А. ${ }^{h}$ Average over: $1.430(4), 1.436(4) \AA .{ }^{i}$ Average over: $1.460(4), 1.468(4) \AA$.

around the double bond and greater the cross-conjugation. The different conformations of A-D are expected to reflect into different excitation and emission spectra. As evident from parameters in Table 1, polymorphs $\mathbf{A}$ and $\mathbf{B}$ possess similar molecular conformations quite different from those of $\mathbf{C}$ and $\mathbf{D}$.

The twisted conformations of $\mathbf{A}-\mathbf{D}$ rule out the presence of strong intermolecular $\pi-\pi$ stacking interactions, excluding the formation of $\mathrm{H}$ - or J-aggregates. On the other hand, the weak intermolecular interactions found in A-D structures (a partial view of the crystal packing of $\mathbf{A}$ is reported in Fig. 4 as an example) are enough to fix the molecular conformations in the crystal structures activating the RIR mechanism. In both A and B structures, molecules are arranged along chains connected through weak $\mathrm{C}-\mathrm{H} \cdots \mathrm{N}$ hydrogen bonds with weak $\pi-\pi$ stacking interactions connecting the chains with each other (see Fig. 4 for crystal packing of $\mathbf{A}$ ). In structures of $\mathbf{C}$ and $\mathbf{D}$, on the other hand, a quite dense intermolecular interaction network, based on several weak $\mathrm{C}-\mathrm{H} \cdots \mathrm{N}$ and $\mathrm{C}-\mathrm{H} \cdots \pi$ interactions, is observed (see $\mathrm{ESI} \dagger$ for a detailed description of crystal packing of A-D

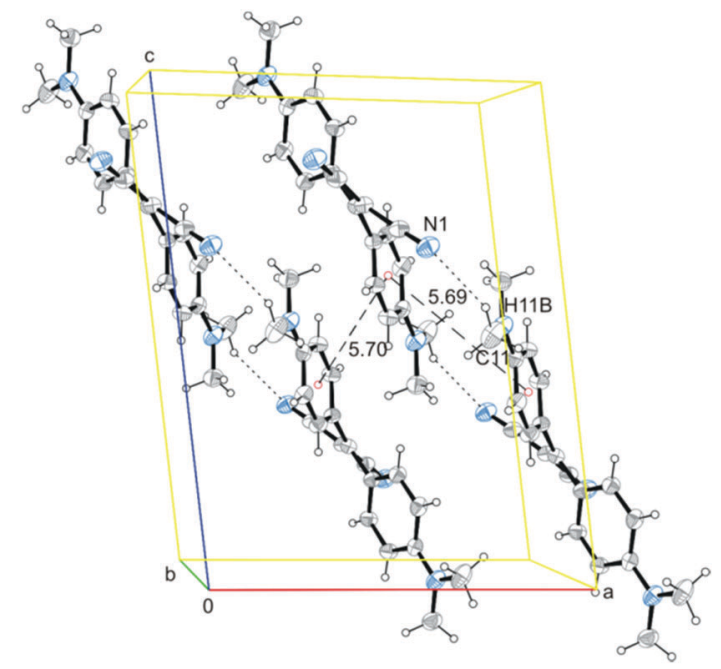

Fig. 4 Partial view of the crystal packing of $\mathbf{A}$ (along the $b$ axis direction), where selected hydrogen bonds (short dashes) and centroids-connecting lines (long dashes) are included. Ellipsoids are drawn at the 30\% probability level. 
Table 2 Dihedral angles $\left(\alpha,{ }^{\circ}\right)$ between the least-squares planes through the phenyl rings, selected bond lengths $(\AA)$ and excitation energies $(\lambda$, nm) with associated oscillator strengths ( $f$ ) and assignments based on MO contributions, computed on 1 at the PBEO and TD-PBE0/6-311++G(d,p) levels of theory in toluene for different fixed values of the $(\mathrm{N}) \mathrm{C}-\mathrm{C}=\mathrm{C}-\mathrm{C}(\mathrm{Ph})$ torsion angle $\left(\beta,{ }^{\circ}\right)^{\mathrm{a}}$

\begin{tabular}{|c|c|c|c|c|c|}
\hline$\beta$ & $\alpha$ & $\mathrm{C}=\mathrm{C}$ & $\mathrm{C}-\mathrm{C}(\mathrm{CN})$ & $\mathrm{C}-\mathrm{C}(\mathrm{Ph})$ & $\lambda_{\text {abs }}(f)$, assignments \\
\hline 10 & 66.3 & 1.387 & 1.422 & 1.459 & $413(0.69), \mathrm{H}-1 \rightarrow \mathrm{L}(99.1 \%) ; 407(0.46), \mathrm{H} \rightarrow \mathrm{L}(99.1 \%)$ \\
\hline $13.85^{b}$ & 65.1 & 1.388 & 1.421 & 1.458 & $415(0.71), \mathrm{H}-1 \rightarrow \mathrm{L}(99.2 \%) ; 408(0.47), \mathrm{H} \rightarrow \mathrm{L}(99.2 \%)$ \\
\hline 30 & 59.2 & 1.399 & 1.418 & 1.451 & $431(0.83), \mathrm{H}-1 \rightarrow \mathrm{L}(99.3 \%) ; 424(0.46), \mathrm{H} \rightarrow \mathrm{L}(99.3 \%)$ \\
\hline
\end{tabular}

${ }^{a}$ See Fig. 3 for geometrical parameter definitions. ${ }^{b}$ Value corresponding to the optimized geometry.

and Fig. S6-S8 (ESI†) for a partial view of the crystal packing of B-D). The structural analysis on the four crystal forms A-D highlights, also in the molecular packing, similarities between $\mathbf{A}$ and $\mathbf{B}$, which are both markedly different from the packing of $\mathbf{C}$ and $\mathbf{D}$ (see Fig. S9 and S10, ESI $\dagger$ ). Such structural similarity is reflected in a similar emissive spectral range for $\mathbf{A}$ and $\mathbf{B}$.

In order to evaluate the influence of molecular and crystal structures on the optical properties, we have performed PBE0/ $6-311++\mathrm{G}(\mathrm{d}, \mathrm{p})$ calculations on $\mathbf{1}$ by freezing the torsion angle $\beta$ to selected values and relaxing all the other freedom degrees (see Table 2). Looking at the reported computed bond lengths, the degree of $\pi$-electron cross-conjugation is expected to increase with increasing $\beta$ angle and decreasing $\alpha$ angle, in the same way as observed in the X-ray crystal structures. The results of TDDFT calculations, also reported in Table 2, are indicative of a red-shift of the computed absorption wavelengths with increasing conjugation degree, suggesting a negligible influence of the crystal packing on the optical behavior.

\section{Polymorphism-dependent fluorescence properties}

Crystals of A-D show an increase of more than one order of magnitude of the PL quantum efficiency with respect to the solution, according to an AIE mechanism. In addition, crystals of $\mathbf{A}$ and $\mathbf{B}$ display irreversible emissive mechanochromism, crystals of $\mathbf{A}$ also show reversible thermochromic behavior while crystals of $\mathbf{C}$ show chronochromism. Crystals of $\mathbf{D}$ undergo a phase transition to form $\mathbf{B}$ upon standing in air or, more rapidly, upon mild thermal treatment (see Scheme 3).

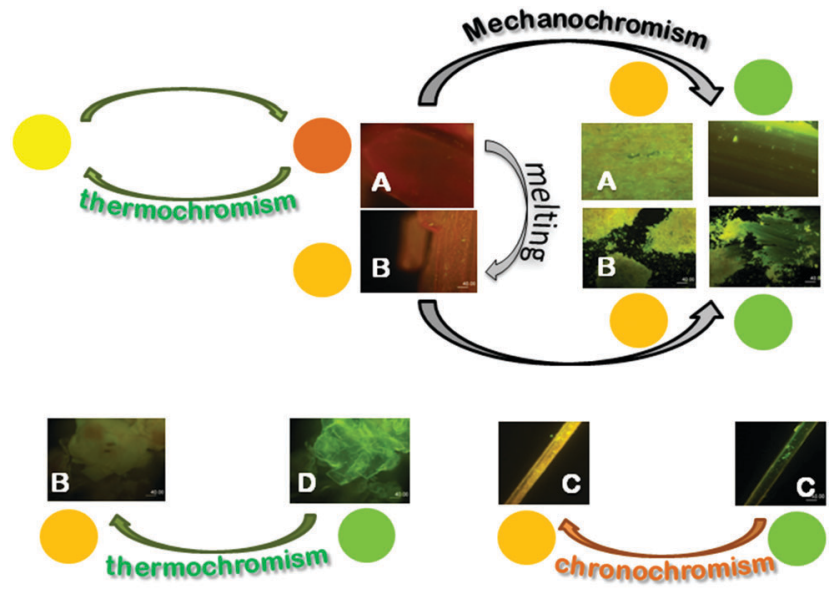

Scheme 3 Representation of the chromic processes of crystals A-D.
Chromic processes of $\mathbf{A}$. The PL emission spectrum of a single crystal of $\mathbf{A}$ as measured by exciting at $405 \mathrm{~nm}$ using confocal microscope apparatus is reported in Fig. 5.

The emission is composed of two contributions at about 595 and $550 \mathrm{~nm}$. In order to investigate the possible phosphorescence origin of the $595 \mathrm{~nm}$ emission (as observed in the glassy solution), we have performed time resolved analysis of the crystal emission. These measurements confirmed the fluorescence origin of all the spectral components of the crystal emission (average lifetimes of about $1.50 \mathrm{~ns}$, independent of the emission wavelength, see ESI $\dagger$ ).

Phosphorescence is detected only upon lowering the temperature of the crystal and shows a structured spectrum with the main peak at $620 \mathrm{~nm}$ and an average lifetime of $1.82 \mu \mathrm{s}$ (see Fig. S11, ESI $\dagger$ ). Interestingly, when crystal $\mathbf{A}$ is gradually heated up to $130{ }^{\circ} \mathrm{C}$, the $595 \mathrm{~nm}$ component disappears, but it is restored when the crystal is cooled back to room temperature. The reversibility of this thermochromic behavior seems reasonable to be ascribed to the presence of different surface emission centers in the crystals rather than to a phase transition. The observation that the lower energy component disappears at high temperature suggests its origin from a smoother surface region, ${ }^{16}$ which is perturbed at high temperature and recovered at room temperature. In addition, $\mathbf{A}$ displays an evident mechanochromic behavior. In fact, as shown in Fig. 5b, when a single crystal of $\mathbf{A}$ is ground with a spatula, yelloworange $(555 \mathrm{~nm})$ fragments are obtained. Upon smashing, the emission color is further blue-shifted to $535 \mathrm{~nm}$, a value quite close to that observed for the diluted glassy solution. The PL quantum efficiency of the single crystal is equal to $3 \%$, increasing to $4 \%$ upon mild grinding, while it decreases below $1 \%$ upon smashing when the emission shifts to green. The original $595 \mathrm{~nm}$ emission cannot be restored by performing annealing treatment of the ground crystals.

The mechano-induced changes of $\mathbf{A}$ were also monitored by X-ray powder diffraction (XRPD) after different grinding steps (see Fig. 6). The XRPD pattern of very slightly ground crystals of A shows intense and sharp reflection peaks, in good agreement with the simulated pattern of polymorph A. After further grinding, the XRPD profile shows the same but significantly enlarged and attenuated signals attributable to the partial amorphization of the solid. At this stage, the number of surface defects is expected to be greatly increased leading to the quenching of the low energy emission component in the PL spectra. 

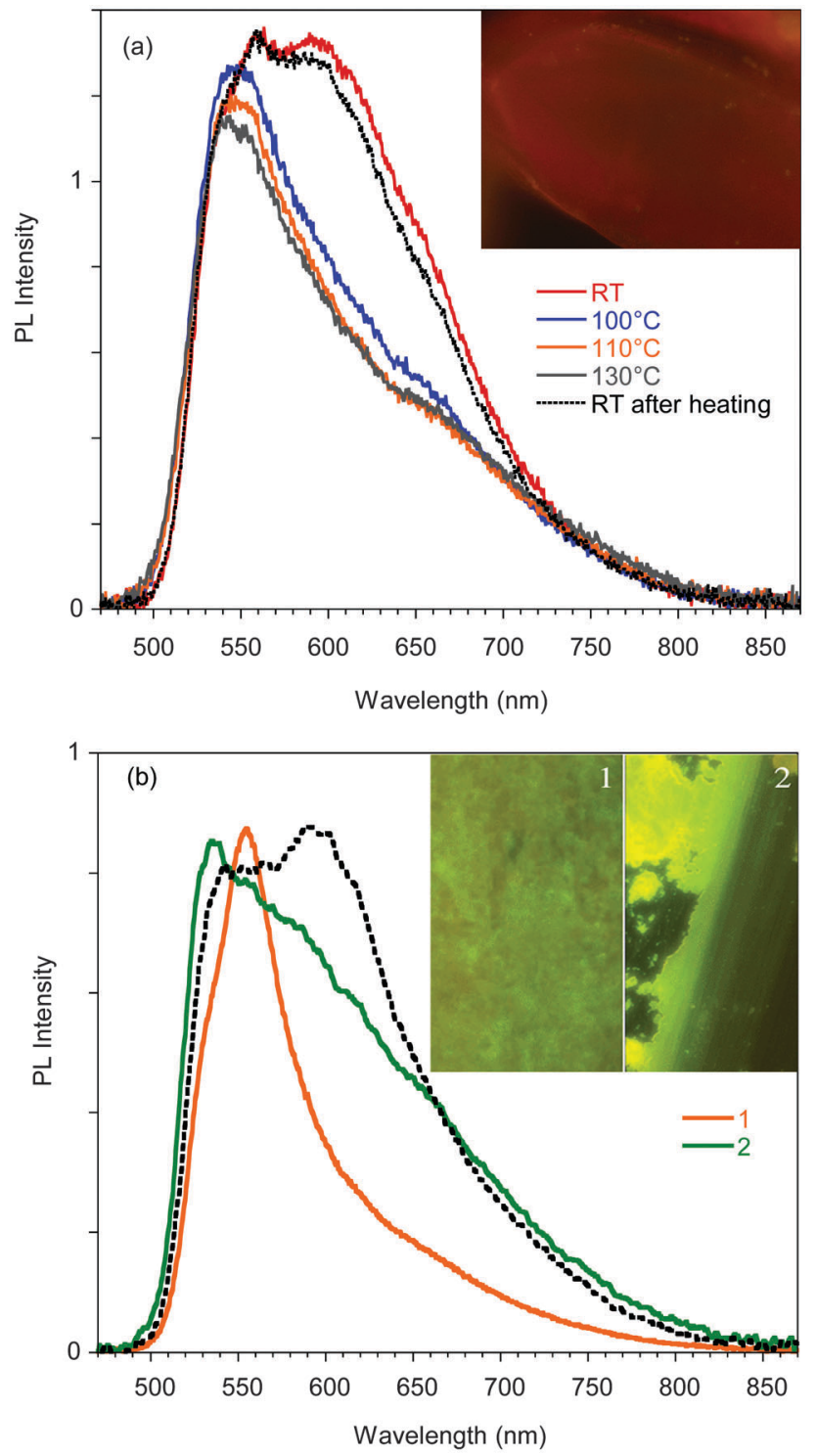

Fig. 5 (a) PL spectra of a single crystal of $\mathbf{A}$ recorded during a heatingcooling cycle. Inset: Microscopy image of a $360 \times 320 \mu \mathrm{m}$ portion of the crystal. (b) Normalized PL spectra of a single crystal of $\mathbf{A}$ before (dotted line) and after mild (1) grinding and smashing. (2). Inset: Pictures taken using a confocal fluorescence microscope during the grinding process. Images size is $80 \times 140 \mu \mathrm{m}$.

When $\mathbf{A}$ is obtained as powder by fast precipitation from a $\mathrm{CH}_{2} \mathrm{Cl}_{2}$ /hexane solution of 1 , as confirmed by XRPD (see Fig. 6), a narrow emission centered at $560 \mathrm{~nm}$ and PL quantum efficiency of $11 \%$ are observed suggesting a stronger emissive behavior in samples with more defective surfaces (see Fig. S13, ESI $\dagger$ ). Surprisingly, in the attempt to prepare the amorphous sample by melting powders of $\mathbf{A}$ at $260{ }^{\circ} \mathrm{C}$ and rapidly quenching the melt with liquid nitrogen, highly crystalline powders of $\mathbf{B}$ were obtained (XRPD evidence) and the emission broadened and slightly red-shifted (see Fig. S12 and S13, ESI $\dagger$ ).

Chromic processes of $\mathbf{B}$. Single crystals of $\mathbf{B}$ display a structured emission with maxima at 535 and $558 \mathrm{~nm}$ with a long tail at lower energy and PL quantum efficiency equal

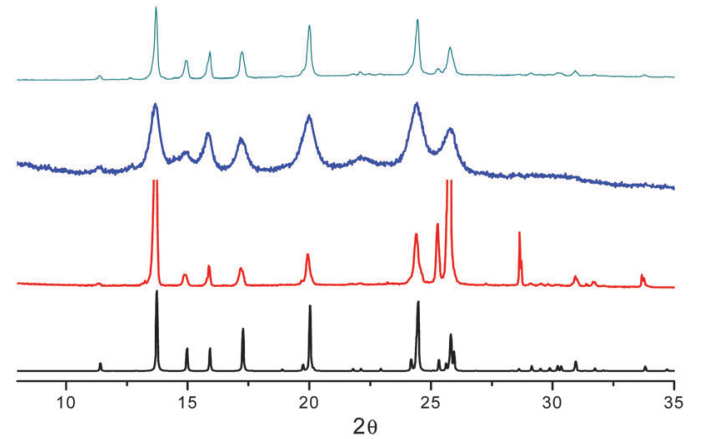

Fig. 6 XRPD patterns monitoring the grinding process for compound A: simulated from crystal structure data (black); crystals after mild (red) and thorough (blue) grinding; powders obtained by fast precipitation (cyan).

to $3 \%$. Time resolved analysis of the emission confirms a fluorescence origin with average lifetimes of about $2.2 \mathrm{~ns}$ at $550 \mathrm{~nm}$ (see ESI $\dagger$ ) while, similarly to phase A, a structured phosphorescence spectrum with the main peak at $620 \mathrm{~nm}$ and an average lifetime of $1.1 \mu \mathrm{s}$ is detected upon lowering the temperature of the crystal to $77 \mathrm{~K}$ (see Fig. S11, ESI $\dagger$ ). When gradually heated up to $120{ }^{\circ} \mathrm{C}$, a decrease of all emission components is observed (see Fig. 7a) while the original spectrum is almost recovered at room temperature.

The mechanochromic behavior of a single crystal of $\mathbf{B}$ was also investigated. When roughly ground with a spatula, a single and sharp emission at $560 \mathrm{~nm}$ is observed. Upon smashing the emission is shifted to $535 \mathrm{~nm}$ (see Fig. 7b). This behavior and the trend in the PLQYs are very similar to what was observed for $\mathbf{A}$.

The mechanochromic emission changes of $\mathbf{B}$ were also monitored by XRPD after different grinding steps (see Fig. 8). The XRPD pattern of roughly ground crystals of $\mathbf{B}$ shows intense and sharp reflection peaks, in good agreement with the simulated pattern of polymorph B. Contrarily to polymorph A, the XRPD profile seems less affected by further grinding indicating a lower tendency of $\mathbf{B}$ to form an amorphous phase.

The observation of an identical emissive behavior from roughly ground $\mathbf{A}$ and $\mathbf{B}$, characterized by different crystal structures, supports the hypothesis of surface defects at the origin of the yellow emission.

Chromic behavior of C. Single crystals of $\mathbf{C}$ display an emission centered at $535 \mathrm{~nm}$ and a PL quantum efficiency equal to $3 \%$. The single crystal of $\mathbf{C}$ does not show relevant mechanochromic effects, and when gradually heated up to $150{ }^{\circ} \mathrm{C}$, only a decrease in the emission intensity is observed (see Fig. S14, ESI $\dagger$ ).

Surprisingly, upon standing in air for several days, the emission color of crystals of $\mathbf{C}$ shifts to yellow $(560 \mathrm{~nm})$ as shown in Fig. 9. Upon thermal annealing of the latter sample a further red-shift of the emission is observed. This chronochromic behavior, different from previous findings in the literature, ${ }^{13,14}$ is not associated with a phase transition as indicated by single crystal X-ray diffraction analysis which gave the same unit cell parameters as the freshly prepared crystals of $\mathbf{C}$. A different emissive behavior associated with the same crystal structure has been previously observed for other crystals and 

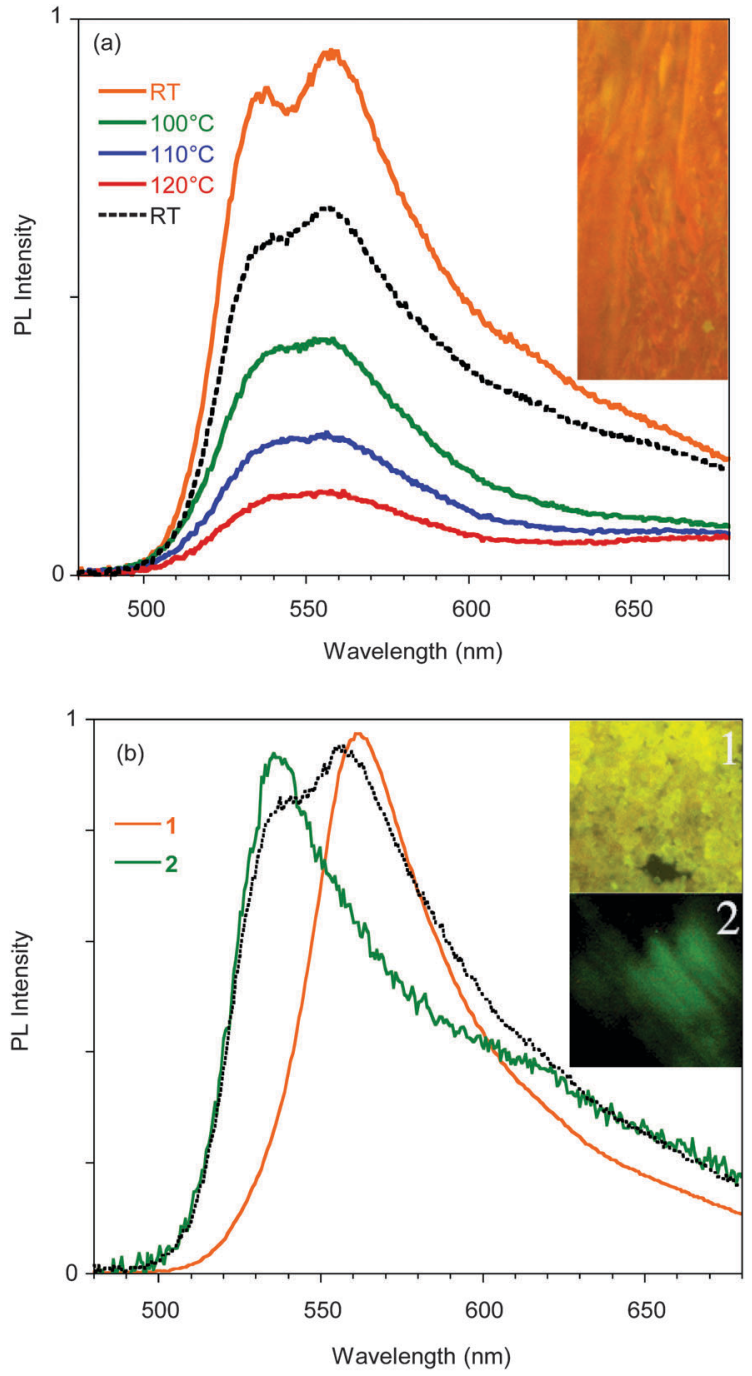

Fig. 7 (a) PL spectra of a single crystal of $\mathbf{B}$ during heating and after the heating cycle (dotted line), inset: microscopy image of a $80 \times 190 \mu \mathrm{m}$ portion of the crystal. (b) Normalized PL spectra of a single crystal of B before (dotted line) and after mild grinding (1) and smashing (2). Inset: Pictures taken using a confocal fluorescence microscope during the grinding process. The size of the images of inset is $80 \times 80 \mu \mathrm{m}$.

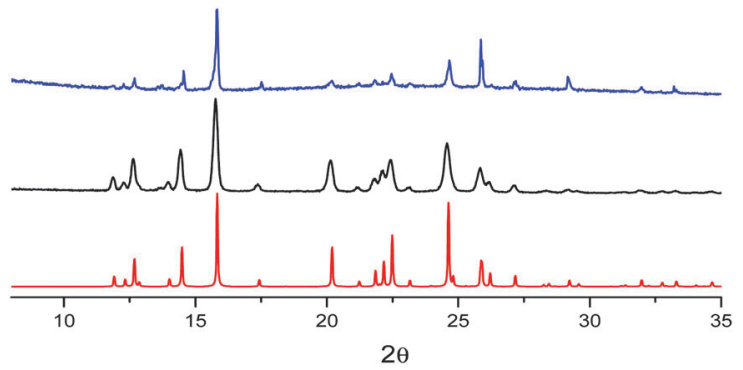

Fig. 8 XRPD patterns monitoring the grinding process for compound $\mathbf{B}$ simulated from crystal structure data (red); crystals after mild (black) and thorough (blue) grinding

ascribed to different surface structures (rough or smooth morphology). ${ }^{16}$ It is reasonable that in our case the harsh

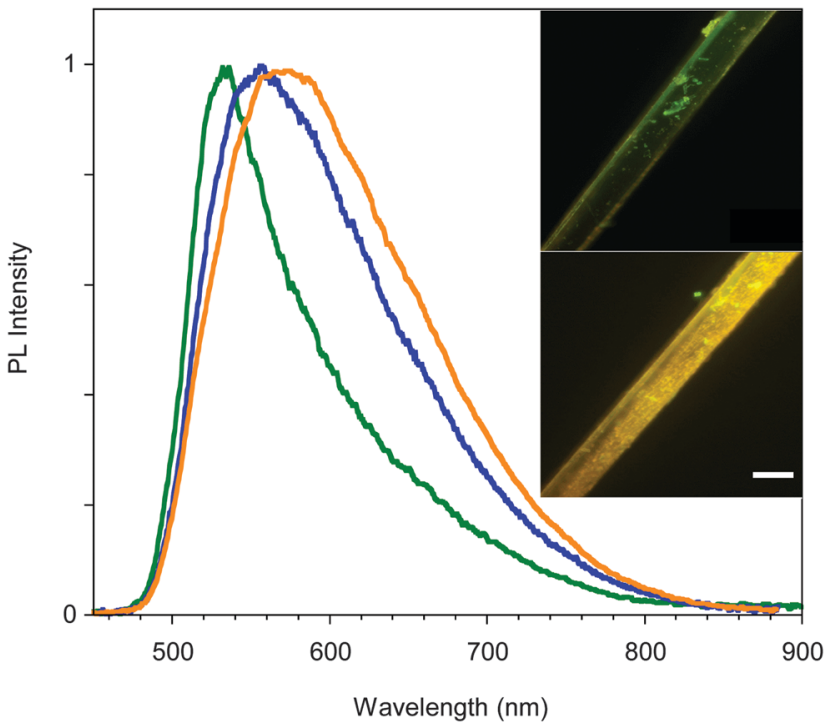

Fig. 9 PL spectra of crystal C: as-prepared (green line), after 20 days (blue line), and the latter after thermal annealing (orange line). In the inset the picture of a portion of one crystal as-prepared (top) and after 20 days (bottom); scale bar is $40 \mu \mathrm{m}$ long.

ambient conditions (humid and very hot summer) have somehow modified the surface morphology leading to the formation of defects characterized by an emissive color different from that of the bulk, as previously reported. ${ }^{16 c, d}$ Further experiments in support of this hypothesis are planned.

Chromic behavior of $\mathbf{D}$. Crystals and powders of $\mathbf{D}$, containing co-crystallized dichloromethane, are rather unstable when kept in air owing to the loss of the solvent. Powders of this phase can be conveniently and selectively prepared by Rotavapor drying from $\mathrm{CH}_{2} \mathrm{Cl}_{2}$ solutions. The Rotavapor drying must be interrupted immediately after solvent evaporation, otherwise leading to the formation of $\mathbf{B}$, which is also the product of decomposition of crystals of $\mathbf{D}$. The assignment of both starting and final powders was inferred by XRPD patterns, in good agreement with that simulated from single crystal data for $\mathbf{D}$ and $\mathbf{B}$, respectively (see Fig. 10). The $\mathbf{B}$ phase can also be more

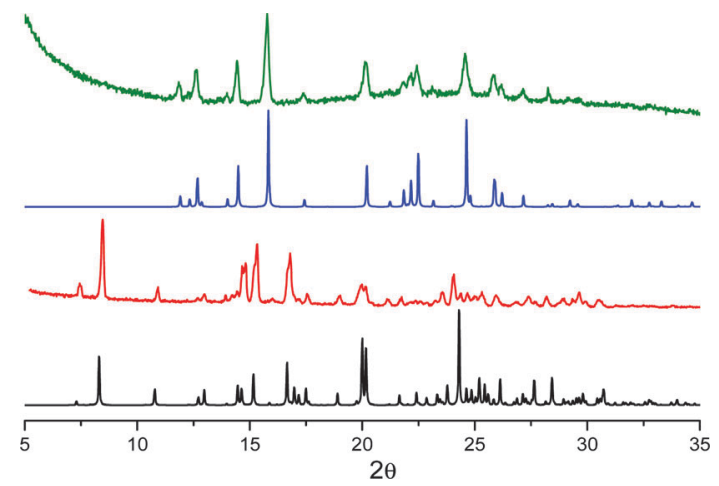

Fig. 10 XRPD patterns monitoring the desolvation process of compound $\mathbf{D}$ and its transformation to $\mathbf{B}$ : simulated from crystal structure data for $\mathbf{D}$ (black); powders of $\mathbf{D}$ freshly prepared (red); simulated from crystal structure data for $\mathbf{B}$ (blue); powders of $\mathbf{D}$ left in the air (green). 


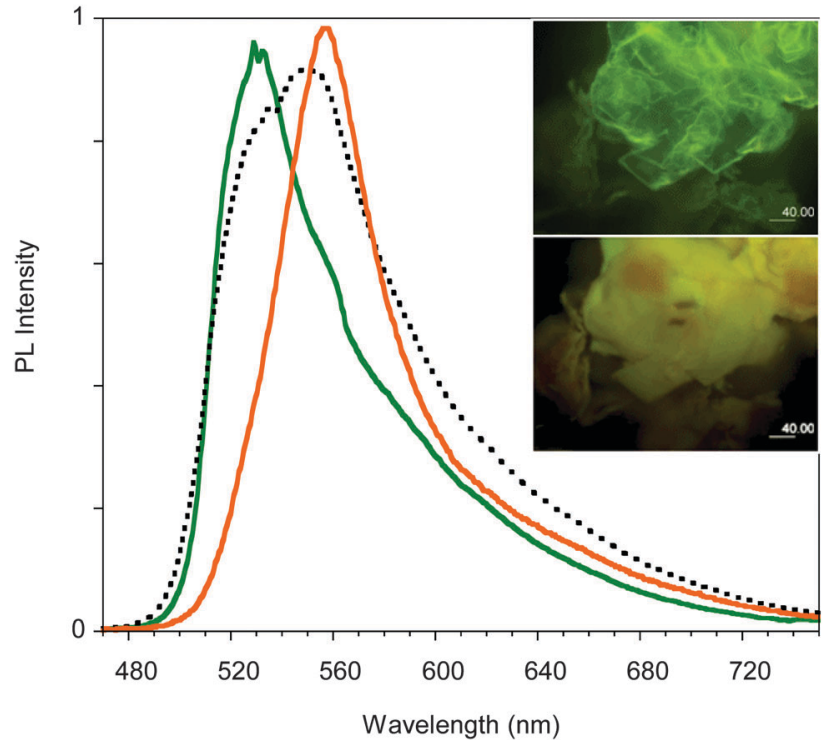

Fig. $11 \mathrm{PL}$ spectra of crystals of $\mathbf{D}$ before thermal treatment (green line), after treatment at $50{ }^{\circ} \mathrm{C}$ for $10 \mathrm{~min}$ (dotted black line) and $25 \mathrm{~min}$ (orange line). Inset: Images taken at the microscope before (top) and after (bottom) thermal treatment

quickly obtained from $\mathbf{D}$ by mild heating at $50{ }^{\circ} \mathrm{C}$ in air, as indicated by the gradual red-shift (from 530 to $558 \mathrm{~nm}$ ) of the emission band measured using a confocal microscope (see Fig. 11).

\section{Conclusions}

Compound 1 was synthesized and its emissive behavior was investigated at both molecular and aggregate levels. Four different crystalline phases have been isolated, two of them already known while the other two reported here for the first time. In particular one of the new structures belongs to an acentric space group.

All these phases display AIE (aggregation-induced emission) features and emissive behavior which can be correlated with the molecular geometry as confirmed by DFT and TDDFT calculations, indicating a red-shift of the emission with increasing conjugation degree, as imposed by the crystalline environment. In particular, emission is shifted from the green region for the less conjugated phases $\mathbf{C}$ and $\mathbf{D}$ to the yellow and yelloworange regions for the more conjugated $\mathbf{B}$ and $\mathbf{A}$, respectively. Analogous behavior has been previously reported for another polymorphism-dependent emissive system characterized by a twisted conformation around a double bond, ${ }^{14}$ for which the greater red-shift of the emission maxima was shown by the more conjugated conformer.

Interestingly, crystals of polymorph $\mathbf{A}$, characterized by a two-component emission at room temperature, display both thermo- and mechanochromic emissive behavior. The low energy component is reversibly quenched at high temperature due to the decreased contribution from smooth surface regions. The number of defective surface centers is also increased by the grinding process, which induces crystal size reduction and amorphization. At manual smashing both phases $\mathbf{A}$ and $\mathbf{B}$ show emission properties similar to those of the glassy solution of 1. C does not display thermo- and mechanochromic behavior but chronochromic properties. D is easily transformed into $\mathbf{B}$ either spontaneously or by mild thermal treatment due to solvent loss. The $\mathbf{D}$ to $\mathbf{B}$ transformation represents the only emission color change associated with a phase transition. All the other emission color changes reported in the present study seem to be ascribable to a variation of the crystal surface morphology; in particular, upon grinding, surface defects are formed in which molecules with a relaxed conformation emit a different color.

\section{Acknowledgements}

The use of instrumentation purchased through the Regione Lombardia - Fondazione Cariplo joint SmartMatLab Project is gratefully acknowledged. DP acknowledges grants by MIUR (PRIN 2009-A5Y3N9), INSTM-Regione Lombardia and ENI S.p.A. for partial support of this work. C. B. thanks Regione Lombardia for funding (project "Tecnologie e materiali per l'utilizzo efficiente dell'energia solare" decreto 3667/2013). Prof. G. Terraneo is acknowledged for the use of the Bruker AXS D8 powder diffractometer at Politecnico di Milano and for his help in collecting the spectra.

\section{Notes and references}

1 (a) L. Yao, S. Zhang, R. Wang, W. Li, F. Shen, B. Yang and Y. Ma, Angew. Chem., 2014, 126, 2151; (b) Z. Zhao, J. W. Y. Lam and B. Z. Tang, J. Mater. Chem., 2012, 22, 23726; (c) X. Wang, Y. Zhou, T. Lei, N. Hu, E. Q. Chen and J. Pei, Chem. Mater., 2010, 22, 3735; (d) W. Z. Yuan, P. Lu, S. Chen, J. W. Y. Lam, Z. Wang, Y. Liu, H. S. Kwok, Y. Ma and B. Z. Tang, Adv. Mater., 2010, 22, 2159; (e) H. Uoyama, K. Goushi, K. Shizu, H. Nomura and C. Adachi, Nature, 2012, 492, 234. 2 (a) C. Zhang, Y. S. Zhao and J. N. Yao, Phys. Chem. Chem. Phys., 2011, 13, 9060; (b) Q. Liao, H. B. Fu and J. N. Yao, Adv. Mater., 2009, 21, 4153; (c) J. Y. Zheng, Y. L. Yan, X. P. Wang, Y. S. Zhao, J. X. Huang and J. N. Yao, J. Am. Chem. Soc., 2012, 134, 2880; (d) Y. L. Lei, Q. Liao, H. B. Fu and J. N. Yao, J. Am. Chem. Soc., 2010, 132, 1742.

3 (a) V. Bulovi, V. G. Kozlov, V. B. Khalfin and S. R. Forrest, Science, 1998, 279, 553; (b) X. F. Duan, Y. Huang, R. Agarwal and C. M. Lieber, Nature, 2003, 421, 241; (c) Y. S. Zhao, A. D. Peng, H. B. Fu, Y. Ma and J. N. Yao, Adv. Mater., 2008, 20, 1661; (d) I. D. W. Samuel and G. A. Turnbull, Chem. Rev., 2007, 107, 1272; (e) X. Gu, J. Yao, G. Zhang, Y. Yan, C. Zhang, Q. Peng, Q. Liao, Y. Wu, Z. Xu, Y. Zhao, H. Fu and D. Zhang, Adv. Funct. Mater., 2012, 22, 4862.

4 (a) X. Sun, Y. Liu, X. Xu, C. Yang, G. Yu, S. Chen, Z. Zhao, W. Qiu, Y. Li and D. Zhu, J. Phys. Chem. B, 2005, 109, 10786; (b) Y. Shirota, J. Mater. Chem., 2005, 15, 75; (c) X. Y. Shen, W. Z. Yuan, Y. Liu, Q. Zhao, P. Lu, Y. Ma, I. D. Williams, 
A. Qin, J. Z. Sun and B. Z. Tang, J. Phys. Chem. C, 2012, 116, 10541; (d) X. Y. Shen, Y. J. Wang, E. Zhao, W. Z. Yuan, Y. Liu, P. Lu, A. Qin, Y. Ma, J. Z. Sun and B. Z. Tang, J. Phys. Chem. C, 2013, 117, 7334; (e) F. S. Kim, X. Guo, M. D. Watson and S. A. Jenekhe, Adv. Mater., 2010, 22, 478; $(f)$ T. C. Lin, G. S. He and Q. Zheng, J. Mater. Chem., 2006, 16, 2490.

5 (a) J. B. Birks, Photophysics of Aromatic Molecules, Wiley, London, 1970; (b) E. A. Silinsh, Organic Molecular Crystals, Springer-Verlag, Berlin, 1980; (c) S. W. Thomas, G. D. Joly and T. M. Swager, Chem. Rev., 2007, 107, 1339.

6 (a) Y. N. Hong, J. W. Y. Lam and B. Z. Tang, Chem. Soc. Rev., 2011, 40, 5361; (b) Z. Y. Zhang, B. Xu, J. H. Su, L. P. Shen, Y. S. Xie and H. Tian, Angew. Chem., Int. Ed., 2011, 50, 11654; (c) B. Wang, Y. C. Wang, J. L. Hua, Y. H. Jiang, J. H. Huang, S. X. Qian and H. Tian, Chem. - Eur. J., 2011, 17, 2647; (d) J. Mei, Y. Hong, J. W. Y. Lam, A. Qin, Y. Tang and B. Z. Tang, Adv. Mater., 2014, 26, 5429.

7 (a) X. Y. Qi, H. Li, J. W. Y. Lam, X. T. Yuan, J. Wei, B. Z. Tang and H. Zhang, Adv. Mater., 2012, 24, 4191; (b) Z. Li, Y. Q. Dong, J. W. Y. Lam, J. X. Sun, A. J. Qin, M. Häußler, Y. P. Dong, H. H. Y. Sung, I. D. Williams, H. S. Kwok and B. Z. Tang, Adv. Funct. Mater., 2009, 19, 905; (c) F. Mahtab, Y. Yu, J. W. Y. Lam, J. Z. Liu, B. Zhang, P. Lu, X. X. Zhang and B. Z. Tang, Adv. Funct. Mater., 2011, 21, 1733; (d) G. Yu, S. W. Yin, Y. Q. Liu, J. S. Chen, X. J. Xu, X. B. Sun, D. G. Ma, X. W. Zhan, Q. Peng, Z. G. Shuai, B. Z. Tang, D. B. Zhu, W. H. Fang and Y. Luo, J. Am. Chem. Soc., 2005, 127, 6335; (e) J. D. Luo, Z. L. Xie, J. W. Y. Lam, L. Cheng, H. Y. Chen, C. F. Qiu, H. S. Kwok, X. W. Zhan, Y. Q. Liu, D. B. Zhu and B. Z. Tang, Chem. Commun., 2001, 1740.

8 (a) A. Prasanna de Silva, H. Q. Nimal Gunaratne, T. Gunnlaugsson, A. J. M. Huxley, C. P. McCoy, J. T. Rademacher and T. E. Rice, Chem. Rev., 1997, 97, 1515; (b) M. Wang, G. X. Zhang, D. Q. Zhang, D. B. Zhu and B. Z. Tang, J. Mater. Chem., 2010, 20, 1858; (c) Y. Liu, Y. H. Tang, N. N. Barashkov, I. S. Irgibaeva, J. W. Y. Lam, R. R. Hu, D. Birimzhanova, Y. Yu and B. Z. Tang, J. Am. Chem. Soc., 2010, 132, 13951; (d) Y. Liu, C. M. Deng, L. Tang, A. J. Qin, R. R. Hu, J. Z. Sun and B. Z. Tang, J. Am. Chem. Soc., 2011, 133, 660; (e) S. J. Toal, K. A. Jones, D. Magde and W. C. Trogler, J. Am. Chem. Soc., 2005, 127, 11661; $(f)$ C. Yu, K. H. Y. Chan, K. M. C. Wong and V. W. W. Yam, Proc. Natl. Acad. Sci. U. S. A., 2006, 103, 19652; (g) M. C. L. Yeung, K. M. C. Wong, Y. K. T. Tsang and V. W. W. Yam, Chem. Commun., 2010, 46, 7709.

9 (a) B. L. Feringa, R. A. van Delden, N. Koumura and E. M. Geertsema, Chem. Rev., 2000, 100, 1789; (b) V. I. Minkin, Chem. Rev., 2004, 104, 2751; (c) S. J. Lim, B. K. An, S. D. Jung, M. A. Chung and S. Y. Park, Angew. Chem., Int. Ed., 2004, 43, 6346; (d) Z. Q. Guo, W. H. Zhu, L. J. Shen and H. Tian, Angew. Chem., Int. Ed., 2007, 46, 5549; (e) G. Y. Jiang, Y. L. Song, X. F. Guo, D. Q. Zhang and D. B. Zhu, Adv. Mater., 2008, 20, 2888; $(f)$ H. Li, J. X. Wang, H. Lin, L. Xu, W. Xu, R. M. Wang, Y. L. Song and D. B. Zhu, Adv. Mater., 2010, 22, 1237; ( $g$ ) Y. Q. Wen, J. X. Wang, J. P. Hu, L. Jiang, H. J. Gao, Y. L. Song and D. B. Zhu, Adv. Mater., 2006,
18, 1983; (h) Y. L. Shang, Y. Q. Wen, S. L. Li, S. X. Du, X. B. He, L. Cai, Y. F. Li, L. M. Yang, H. J. Gao and Y. L. Song, J. Am. Chem. Soc., 2007, 129, 11674.

10 T. Mutai, H. Satou and K. Araki, Nat. Mater., 2005, 4, 685.

11 (a) X. Zhang, B. Li, Z.-H. Chen and Z.-N. Chen, J. Mater. Chem., 2012, 22, 11427; (b) J. Ni, X. Zhang, Y.-H. Wu, L.-Y. Zhang and Z.-N. Chen, Chem. - Eur. J., 2011, 17, 1171; (c) S. Jayanty and T. P. Radhakrishnan, Chem. Eur. J., 2004, 10, 791.

12 (a) S. Yamaguchi, I. Yoshikawa, T. Mutai and K. Araki, J. Mater. Chem., 2012, 22, 20065; (b) Y. Sagara and T. Kato, Nat. Chem., 2009, 1, 605; (c) X. Zhang, Z. Chi, X. Zhou, S. Liu, Y. Zhang and J. Xu, J. Phys. Chem. C, 2012, 116, 23629; (d) C. Wang, S. Chen, K. Wang, S. Zhao, J. Zhang and Y. Wang, J. Phys. Chem. C, 2012, 116, 17796; (e) S. J. Yoon, J. W. Chung, J. Gierschner, K. S. Kim, M. G. Choi, D. Kim and S. Y. Park, J. Am. Chem. Soc., 2010, 132, 13675; $(f)$ K. Nagura, S. Saito, H. Yusa, H. Yamawaki, H. Fujihisa, H. Sato, Y. Shimoikeda and S. Yamaguchi, J. Am. Chem. Soc., 2013, 135, 10322; (g) H. Ito, M. Muromoto, S. Kurenuma, S. Ishizaka, N. Kitamura, H. Sato and T. Seki, Nat. Commun., 2013, 4, 2009; (h) L. Wang, K. Wang, B. Zou, K. Ye, H. Zhang and Y. Wang, Adv. Mater., 2015, 27, 2918; (i) S. Varughese, J. Mater. Chem. C, 2014, 2, 3499; (j) Y. Q. Dong, J. W. Y. Lam and B. Z. Tang, J. Phys. Chem. Lett., 2015, 6, 3429.

13 J. Wang, J. Mei, R. Hu, J. Zhi Sun, A. Qin and B. Z. Tang, J. Am. Chem. Soc., 2012, 134, 9956.

14 P. Galer, R. C. Korošec, M. Vidmar and B. Sket, J. Am. Chem. Soc., 2014, 136, 7383.

15 (a) X. Luo, J. Li, C. Li, L. Heng, Y. Q. Dong, Z. Liu, Z. Bo and B. Z. Tang, Adv. Mater., 2011, 23, 3261; (b) N. D. Nguyen, G. Zhang, J. Lu, A. E. Sherman and C. L. Fraser, J. Mater. Chem., 2011, 21, 8409.

16 (a) A. Patra, N. Hebalkar, B. Sreedhar, M. Sarkar, A. Samanta and T. P. Radhakrishnan, Small, 2006, 2, 650; (b) Z. Lin, X. Mei, E. Yang, X. Li, H. Yao, G. Wen, C. T. Chien, T. J. Chow and Q. Ling, CrystEngComm, 2014, 16, 11018; (c) T. Han, Y. Hong, N. Xie, S. Chen, N. Zhao, E. Zhao, J. W. Y. Lam, H. H. Y. Sung, Y. Dong, B. Tong and B. Z. Tang, J. Mater. Chem. C, 2013, 1, 7314; (d) Y. Wang, I. Zhang, B. Yu, X. Fang, X. Su, Y.-M. Zhang, T. Zhang, B. Yang, M. Li and S. X.-A. Zhang, J. Mater. Chem. C, 2015, 3, 12328.

17 (a) A. G. Mirochnik, E. V. Fedorenko, V. G. Kuryavyi, B. V. Bukvetskii and V. E. Karasev, J. Fluoresc., 2006, 16, 279; (b) P. S. Hariharan, D. Moon and S. P. Anthony, J. Mater. Chem. C, 2015, 3, 8381.

18 (a) E. Cariati, V. Lanzeni, E. Tordin, R. Ugo, C. Botta, A. Giacometti Schieroni, A. Sironi and D. Pasini, Phys. Chem. Chem. Phys., 2011, 13, 18005; (b) C. Coluccini, A. K. Sharma, M. Caricato, A. Sironi, E. Cariati, S. Righetto, E. Tordin, C. Botta, A. Forni and D. Pasini, Phys. Chem. Chem. Phys, 2013, 15, 1666; (c) F. Villafiorita-Monteleone, A. Cappelli, M. Paolino, M. Colombo, E. Cariati, A. Mura, G. Bongiovanni and C. Botta, J. Phys. Chem. C, 2015, 119, 18986.

19 T. Virgili, A. Forni, E. Cariati, D. Pasini and C. Botta, J. Phys. Chem. C, 2013, 117, 27161. 
20 J. Moreau, U. Giovanella, J.-P. Bombenger, W. Porzio, V. Vohra, L. Spadacini, G. Di Silvestro, L. Barba, G. Arrighetti, S. Destri, M. Pasini, M. Saba, F. Quochi, A. Mura, G. Bongiovanni, M. Fiorini, M. Uslenghi and C. Botta, ChemPhysChem, 2009, 10, 647.

21 Bruker, SMART, SAINT and SADABS, Bruker AXS Inc., Madison, Wisconsin, USA, 1997.

22 G. M. Sheldrick, Acta Crystallogr., 2008, A64, 112.

23 M. J. Frisch, et al., Gaussian 09, Revision D.01., Gaussian, Inc., Wallingford, CT, USA, 2013.

24 (a) M. Ernzerhof and G. E. Scuseria, J. Chem. Phys., 1999, 110, 5029; (b) C. Adamo and V. Barone, J. Chem. Phys., 1999, 110, 6158.

25 (a) L. E. Johnson, L. R. Dalton and B. H. Robinson, Acc. Chem. Res., 2014, 47, 3258; (b) D. Jacquemin, A. Planchat, C. Adamo and B. Mennucci, J. Chem. Theory Comput., 2012, 8, 2359.

26 V. Barone and M. Cossi, J. Phys. Chem. A, 1998, 102, 1995.

27 (a) M. Cossi and V. Barone, J. Chem. Phys., 2001, 115, 4708; (b) R. Cammi and B. Mennucci, J. Chem. Phys., 1999, 110, 9877. 28 I. Shibuya, Y. Taguchi, T. Tsuchiya, A. Oishi and E. Katoh, Bull. Chem. Soc. Jpn., 1994, 67, 3048.

29 (a) V. Ermolaev, Opt. Spektrosk., 1961, 11, 492; V. Ermolaev, Opt. Spectry., 1961, 11, 266; (b) S. K. Lower and M. A. El-Sayed, Chem. Rev., 1966, 66, 199.
30 E. C. Lim and S. K. Chakrabarti, J. Chem. Phys., 1967, 47, 4726 .

31 As determined by X-ray diffraction studies, the dihedral angles between the least-squares planes through the heavy atoms of the $\mathrm{N}$-dimethyl groups and the benzene rings in the four crystal structures A-D are $4.40(9)^{\circ}$ (A); $4.34(8)^{\circ}$ (B); 9.1(2), 2.8(2), 8.4(2) and 7.4(2) $)^{\circ}(\mathbf{C}) ; 5.3(1)$ and $12.2(2)^{\circ}(\mathrm{D})$.

32 (a) A. J. Zucchero, P. L. McGrier and U. H. F. Bunz, Acc. Chem. Res., 2010, 43, 397; (b) W. C. W. Leu and C. S. Hartley, Org. Lett., 2013, 15, 3762; (c) T. Inouchi, T. Nakashima and T. Kawai, J. Phys. Chem. A, 2014, 118, 2591; (d) A. Felouat, A. D’Aléo, A. Charaf-Eddin, D. Jacquemin, B. Le Guennic, E. Kim, K. J. Lee, J. H. Woo, J.-C. Ribierre, J. W. Wu and F. Fages, J. Phys. Chem. A, 2015, 119, 6283.

33 M. A. El-Sayed, J. Chem. Phys., 1963, 38, 2834.

34 Y. Gong, G. Chen, Q. Peng, W. Zhang Yuan, Y. Xie, S. Li, Y. Zhang and B. Z. Tang, Adv. Mater., 2015, 27, 6195.

35 T. Suzuki, K. Ono, H. Kawai and T. Tsuji, J. Chem. Soc., Perkin Trans. 2, 2001, 1798.

36 F. Burě̌, W. B. Schweizer, J. C. May, C. Boudon, J.-P. Gisselbrecht, M. Gross, I. Biaggio and F. Diederich, Chem. Eur. J., 2007, 13, 5378.

37 F. H. Allen, O. Kennard, D. G. Watson, L. Brammer, A. G. Orpen and R. Taylor, J. Chem. Soc., Perkin Trans. 2, 1987, S1. 38 N. F. Phelan and M. Orchin, J. Chem. Educ., 1968, 45, 633. 